\title{
Estimation of Radiation Dose for Adult Patients Undergoing Diagnostic X-ray Examinations of the Skull and Cervical Spine
}

\author{
Mohammed A. Alkreem ${ }^{1}$, Ahmed Abukonna ${ }^{2 *}$ \\ ${ }^{I}$ Radiation and Isotopes Center, Khartoum (RICK), Sudan \\ ${ }^{2}$ College of Medical Radiologic Science, Sudan University of Science and Technology, Sudan
}

\begin{abstract}
The aim of this study was to estimate the Entrance Skin Dose (ESD), the eye lens dose and the thyroid gland dose for adult patients undergoing diagnostic X-ray examinations of the skull and the cervical spine in some hospitals in Sudan. A total of 120 patients were evaluated. The ESD was calculated using the relationship between the X-ray tube output and the exposure parameters. The eye lens dose and the thyroid gland dose were calculated from the ESD using Xdose software (Version 2). The results showed that the mean ESD was $0.636 \mathrm{mGy}, 0.589 \mathrm{mGy}$ and $0.694 \mathrm{mGy}$ for the antero-posterior (AP) cervical spine, lateral cervical spine and lateral skull respectively. The mean eye lens dose was (0.0148) $m G y$, (0.0007) $m G y$ and (0.27) $m G y$ for antero-posterior (AP) cervical spine, lateral cervical spine and lateral skull respectively. The mean thyroid gland dose was (0.416) $m G y,(0.0132) m G y$ and (0.0104) $m$ Gy for antero-posterior (AP) cervical spine, lateral cervical spine and lateral skull respectively. The estimated ESD values were within the range of the international diagnostic dose reference levels and lower than the range at some previous studies and the dose to the eye lens less than the threshold dose of detectable lens opacities and the thyroid gland dose less than that cause damage.
\end{abstract}

Keywords: ESD, eye lens dose, thyroid gland dose, reference dose levels.

\section{Introduction}

Patient radiation dose is an important parameter to control the quality of the X-ray services within the hospital. Dose monitoring helps to ensure the best possible protection of the patient and provides an indication of incorrect use of technical parameters or equipment malfunction [1]. During recent years, patient dose has become a major issue [2]. The radiation dose to patients should follow the ALARA principle "as low as reasonably achievable [3]. With increasing awareness of the need for radiation protection, a paradigm shift can be absorbed from the principle of "image quality as good as possible" to "image quality as good as needed" [4]. The establishment of the quality criteria for diagnostic radiology images started in 1984 when the first Directive on Radiation Protection of the Patient was adopted by the Member States of the European Union [5]. Patient radiation dose from conventional radiographic procedures ranges from $0.1 \mathrm{mSv}$ to $10 \mathrm{mSv}$, resulting in a collective dose to the population that can be significant [6]. The ESD is defined as the absorbed dose to air where the X-ray beam intersects the skin surface of the patient including the backscatter [8]. The reasons for evaluating ESD is that; the physical parameter recommended for monitoring the Diagnostic Reference Levels (DRLs) in conventional radiography was the ESD and the dose is greatest at the surface where radiation enters the body of the patient therefore the skin is the main organ for which there is a possibility of deterministic effect i.e., skin burn [7] another reason the organs equivalent dose can be estimate from the ESD and that very important especially in case where the part of the body to be imaged contain sensitive organ to the effect of radiation. This study was aimed to estimate the ESD, the eye lens dose and the thyroid gland dose for adult patients undergoing diagnostic X-ray examinations of the skull and the cervical spine in some hospitals in Khartoum, Sudan to help applying optimization of radiation protection of the patients.

\section{Materials and Methods}

A total of 120 patients were enrolled in this study. The examinations chosen for this study are the cervical spine antero-posterior projection (AP), lateral projection (LAT) and lateral skull projection (LAT). For each studied examination, personal data (sex, age, weight and height) and technical parameters ( $\mathrm{kVp}, \mathrm{mAs}$ and FSD) were recorded. The Standard FFD of $100 \mathrm{~cm}$ for the cervical spine AP and $110 \mathrm{~cm}$ for the cervical spine LAT and the skull LAT were used as routine. The patients were randomly selected from adult patients of both sexes attending medical investigations in three radiological centers namely Antalya Medical Center (AMC), Bahery Accident \& Emergency Hospital (BAEH) and Sharg Alneel Hospital (SAH). For each hospital, available machine specific data such as type, model, filtration, focal spot size, year of manufacture were recorded from the manufacturer information

* Corresponding Author email: konaa17@ hotmail.com 
written on the machine, all imaging systems are computed radiography based system and all X-ray machines are fixed. These data are presented in table 1 .

The ESD for each patient was calculated using real examination data, according to Eq. 1 [9][10].

$\mathrm{ESD}=\mathrm{OP} \times\left(\frac{\mathrm{kV}}{80}\right)^{2} \times \mathrm{mAs} \times\left(\frac{100}{\mathrm{FSD}}\right)^{2} \times \mathrm{BSF}$

Where ESD is the entrance surface dose, $\mathrm{OP}$ is the output of the $\mathrm{X}$-ray tube (in $\mu \mathrm{Gy} \mathrm{mAs}{ }^{-1}$ ) at $80 \mathrm{kV}_{\mathrm{p}}$ at a distance of $\left(100 \mathrm{~cm}\right.$ ) normalized to $20 \mathrm{mAs}, \mathrm{kV}_{\mathrm{p}}$ is the tube potential (in $\mathrm{KV}$ ), $\mathrm{mAs}$ is the product of the tube current (in $\mathrm{mA}$ ) and the exposure time (in ms), FSD is the focal spot-to-skin distance and BSF is the backscatter factor. The backscatter factor was 1.35 suggested in European guidelines (EC, 1996) [7]. The FSD was calculated using Eq .2 FSD $=$ FFD $-(b+d)$

Where FFD is tube focus-to-image receptor distance, $\mathrm{b}$ is the patient thickness and $\mathrm{d}$ is image receptor-to-top table distance. $\mathrm{b}$ and $\mathrm{d}$ were measured using meter ruler. The eye lens dose and thyroid gland dose for each projection were calculated using Xdose software (Version 2). The X-ray tube output was measured at a distance of $100 \mathrm{~cm}$ from the tube focus using $80 \mathrm{kVp}$ and $20 \mathrm{mAs}$ using the DIAVOLT universal (Model T43014-01292).

Table 1: Specifications of X-ray machines used

\begin{tabular}{|c|c|c|c|}
\hline Hospitals & AMC & BAEH & $\mathrm{SAH}$ \\
\hline Manufacturer & Toshiba & Shimadzu Corporation & Philips \\
\hline Model & E7239X & P18DE-85 & 989000086101 \\
\hline Focal spot size & $2.0 / 1.0$ & $0.6 / 1.2$ & NA \\
\hline Total filtration & $\begin{array}{c}1.9 \mathrm{~mm} \mathrm{AL} \text { at } \\
75 \mathrm{kV}_{\mathrm{P}}\end{array}$ & $\begin{array}{c}2.5 \mathrm{~mm} \text { AL at } \\
75 \mathrm{kV}_{\mathrm{P}}\end{array}$ & $\begin{array}{c}2.5 \mathrm{~mm} \mathrm{AL} \text { at } \\
75 \mathrm{kV}_{\mathrm{P}}\end{array}$ \\
\hline $\begin{array}{c}\text { Generator } \\
\text { Manufacturer }\end{array}$ & Allengers & Shimadzu Corporation & Philips \\
\hline $\mathrm{CR}$ reader & $\begin{array}{c}\text { Fujifilm FCR PRIMA } \\
35 \times 43 \mathrm{~cm} 14 \times 17 \text { Inch }\end{array}$ & $\begin{array}{c}\text { Fujifilm FCR PRIMA } \\
35 \times 43 \mathrm{~cm} 14 \times 17 \text { Inch }\end{array}$ & $\begin{array}{l}\text { Fujifilm FCR PRIMA } \\
35 \times 43 \mathrm{~cm} 14 \times 17 \text { Inch }\end{array}$ \\
\hline $\begin{array}{l}\text { Tube output } \\
\left(\mu \mathrm{GymAs}^{-1}\right)\end{array}$ & 33.9 & 47.58 & 54.28 \\
\hline
\end{tabular}

\section{Results}

Table 2: Characteristics of the patients and technical parameters selected for various examinations

\begin{tabular}{|c|c|c|c|c|c|}
\hline 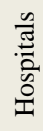 & 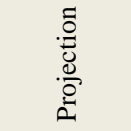 & $\begin{array}{c}\mathrm{KV}_{\mathrm{P}} \\
\text { mean } \pm \mathrm{SD}\end{array}$ & $\begin{array}{c}\mathrm{mAs} \\
\text { mean } \pm \mathrm{SD}\end{array}$ & $\begin{array}{l}\mathrm{FSD}(\mathrm{cm}) \\
\text { mean } \pm \text { SD }\end{array}$ & Grid \\
\hline \multirow{3}{*}{$\sum_{<}^{U}$} & $\mathrm{C} / \mathrm{S}^{*} \mathrm{AP}$ & $67.6 \pm 1.45$ & $15 \pm 0.0$ & $85.2 \pm 1.41$ & No \\
\hline & C/S LAT & $70 \pm 1.06$ & $15 \pm 0.0$ & $88.13 \pm 3.58$ & Yes \\
\hline & Skull LAT & $70.06 \pm 3.12$ & $14.26 \pm 1.57$ & $83.23 \pm 1.33$ & Yes \\
\hline \multirow{3}{*}{ 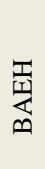 } & C/S AP & $62.6 \pm 1.45$ & $12 \pm 0.0$ & $85.2 \pm 1.41$ & Yes \\
\hline & C/S LAT & $57.6 \pm 2.13$ & $9.06 \pm 0.7$ & $87.2 \pm 2.67$ & Yes \\
\hline & Skull LAT & $51.53 \pm 2.66$ & $4.96 \pm 0.12$ & $83.2 \pm 1.53$ & Yes \\
\hline \multirow{3}{*}{$\underset{⿱ 亠}{\frac{T}{\pi}}$} & $\mathrm{C} / \mathrm{S} \mathrm{AP}$ & $64.46 \pm 1.72$ & $9.66 \pm 0.48$ & $84.66 \pm 1.55$ & No \\
\hline & C/S LAT & $68.93 \pm 1.38$ & $9.73 \pm 0.88$ & $87.93 \pm 3.34$ & Yes \\
\hline & Skull LAT & $69 \pm 1.195$ & $14.8 \pm 1.2$ & $83.56 \pm 1.68$ & Yes \\
\hline
\end{tabular}

$\mathrm{C} / \mathrm{S}^{*}$ : Cervical Spine.

Table 3: The mean ESD (in $m G y \pm S D$ ) in the three Hospitals

\begin{tabular}{|c|c|c|c|}
\hline \multirow{2}{*}{ Hospitals } & \multicolumn{3}{|c|}{$\begin{array}{c}\text { ESD (mGy) } \\
\text { mean } \pm \text { SD }\end{array}$} \\
\cline { 2 - 4 } Examination & C/S AP & C/S LAT & Skull LAT \\
\hline AMC & $0.676 \pm 0.032$ & $0.679 \pm 0.053$ & $0.731 \pm 0.135$ \\
\hline BAEH & $0.69 \pm 0.056$ & $0.399 \pm 0.0561$ & $0.192 \pm 0.0278$ \\
\hline SAH & $0.544 \pm 0.0536$ & $0.691 \pm 0.107$ & $1.161 \pm 0.152$ \\
\hline
\end{tabular}


Table 4: The (mean \pm SD) eye lens dose and thyroid gland dose (in $\mathrm{mGy}$ ) in the three Hospitals

\begin{tabular}{|c|c|c|c|c|}
\hline & & $\mathrm{C} / \mathrm{S} \mathrm{AP}$ & C/S LAT & Skull LAT \\
\hline \multirow{2}{*}{$\sum_{<}$} & $\begin{array}{c}\text { Eye lens dose } \\
\text { mean } \pm \mathrm{SD}\end{array}$ & $0.0165 \pm 0.001$ & $0.00076 \pm 0.0001$ & $0.283 \pm 0.054$ \\
\hline & $\begin{array}{c}\text { Thyroid dose } \\
\text { mean } \pm S D\end{array}$ & $0.436 \pm 0.022$ & $0.0159 \pm 0.0012$ & $0.0113 \pm 0.003$ \\
\hline \multirow{2}{*}{ 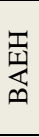 } & $\begin{array}{c}\text { Eye lens dose } \\
\text { mean } \pm \text { SD }\end{array}$ & $0.0145 \pm 0.001$ & $0.0003 \pm 0.0007$ & $0.07082 \pm 0.01$ \\
\hline & $\begin{array}{c}\text { Thyroid dose } \\
\text { mean } \pm \text { SD }\end{array}$ & $0.456 \pm 0.063$ & $0.00716 \pm 0.001$ & $0.00162 \pm 0.0004$ \\
\hline \multirow{2}{*}{ 焉 } & $\begin{array}{c}\text { Eye lens dose } \\
\text { mean } \pm S D\end{array}$ & $0.0136 \pm 0.001$ & $0.0009 \pm 0.0001$ & $0.457 \pm 0.061$ \\
\hline & $\begin{array}{c}\text { Thyroid dose } \\
\text { mean } \pm \text { SD }\end{array}$ & $0.356 \pm 0.043$ & $0.0177 \pm 0.003$ & $0.0185 \pm 0.003$ \\
\hline
\end{tabular}

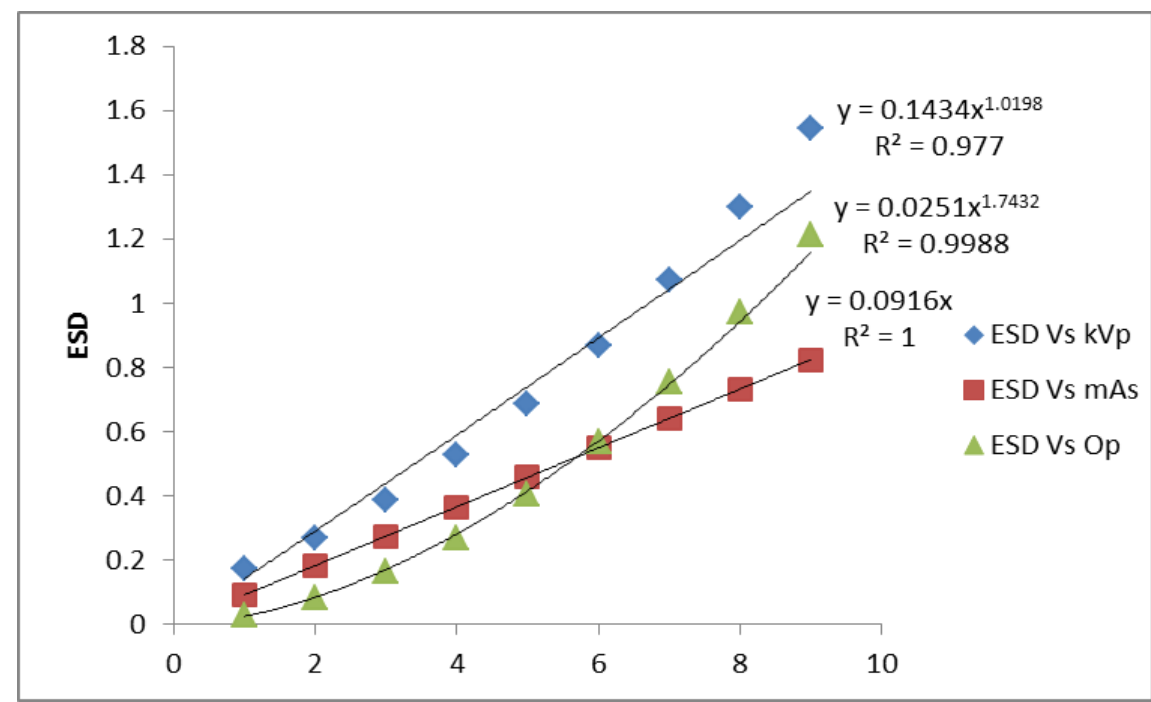

Figure 2: Illustration of the relationship between the $\mathrm{ESD}$ and the $\mathrm{kV}_{\mathrm{p}}, \mathrm{mAs}$ and the $\mathrm{X}$-ray tube output

Table 5: Comparison of ESD (in mGy) with the DRLs and some previous studies

\begin{tabular}{|l|c|c|c|}
\hline \multicolumn{1}{|c|}{ The Studies } & $\begin{array}{c}\text { Cervical spine } \\
\text { (AP) }\end{array}$ & $\begin{array}{c}\text { Cervical spine } \\
\text { (LAT) }\end{array}$ & Skull (LAT) \\
\hline This study & 0.636 & 0.589 & 0.694 \\
\hline Abu KhiarA A (2016) [13] & 1.35 & 1.67 & 1.2 \\
\hline Olivera Ciraj et al (2004) [14] & 1.3 & 1.03 & 0.95 \\
\hline A. Beganović et al (1997) [15] & 0.9 & 0.2 & 0.909 \\
\hline Damijan Škrk et al (2014) [17] & 1.4 & 1.4 & 1.73 \\
\hline
\end{tabular}

\section{Discussion}

The highest $\mathrm{kVp}$ and $\mathrm{mAs}$ for the cervical spine AP and cervical spine LAT were observed in AMC. BAEH observed lowest $\mathrm{kV}_{\mathrm{p}}$ and $\mathrm{mAs}$ for cervical spine LAT and the skull LAT. This variation in the exposure parameters may be due to the variations in the patient's weights, thicknesses and radiographic techniques employed by the operators. Table 3 showed that, the highest ESD for the cervical spine AP $(0.676 \mathrm{mGy})$ was observed in AMC, the highest ESD for the cervical spine LAT $(0.691 \mathrm{mGy})$ and the skull LAT $(1.161 \mathrm{mGy})$ were observed in SAH. The lowest ESD for the cervical spine LAT $(0.399 \mathrm{mGy})$ and the skull LAT $(0.192 \mathrm{mGy})$ were observed in BAEH. Table 2 showed that, The FSD was almost constant for the same test between the three hospitals. AMC and SAH used approximately the same exposure parameters $\left(\mathrm{kV}_{\mathrm{p}}\right.$, mAs and FSD) although it was noted a different ESD for the lateral skull. This difference may be due to the difference in the X-ray tube output between the two hospitals. The ESDs values compared with the international diagnostic dose reference levels (DRLs) [11] and other studies in the Sudan [1][9][10][12][13] and other countries [14][15][16][17], the results showed that; all estimated ESDs values within the range of the DRLs and lower than the range of some previous studies.

Table 4 showed that, the eye lens dose and thyroid gland dose increases with increase the ESD for the same projection. The maximum eye lens dose (0.457) mGy was observed for the skull LAT in SAH that may be due to manual exposure control settings, patient size and other equipment-related factors. The maximum thyroid gland dose (0.436) mGy was observed for cervical spine AP in AMC that may be due to the position of thyroid gland at the center of the beam entry. The mean ESD compared with published works are shown in Table 5; the mean ESD for 
the examinations were lower than those of published works elsewhere. This could generally be attributed to good radiographic techniques employed during the procedures. Therefore, increasing the tube filtration and proper selection of exposure parameters $(\mathrm{kVp}$ and $\mathrm{mAs})$ are effective methods for reducing patient dose during radiographic procedures. The improvement in image receptor technology provides potential for dose reduction but requires proper adjustment of exposure parameters and operator skills.

\section{Conclusion}

The study estimated the ESD for patients underwent skull and cervical procedures in three hospitals in Sudan. The results of this dose survey provide essential data for patient dose levels for radiography and the performance of the equipment used. Dose values were accepted as compared with previous studies in Sudan or other countries. ESD values depend on exposure parameters and number of exam performed as well as patient demographic data. These findings support the importance of the ongoing quality assurance program to ensure that doses should be kept to a level consistent with optimum image quality.

\section{References}

[1]. M. A. Halato, I. I. Suliman, S. T. Kafi, A. M. Ahmed, F. A. S. Ahamed, and Z. Ibrahim, "Dosimetry for Patients undergoing Radiographic Examinations in Sudan,” Radiat. Phys. Prot. Conf. Nasr City - Cairo, Egypt, no. November, 2000, 15-19,

[2]. International Atomic Energy Agency, "Radiological Protection of Patients in Diagnostic and Interventional Radiology, Nuclear Medicine and Radiotherapy," Int. Conf., no. March, 2001, 26-30,

[3]. International Commission on Radiological Protection, "ICRP 103: The 2007 Recommendations of the International Commission on Radiological Protection,” Ann. ICRP, vol. 37, 2007, 330,.

[4]. C. Uffmann, M.; Schaefer-Prokop, "Digital radiography: The balance between image quality and required radiation dose. European Journal of Radiology, 72, 2009, 202-208,"

[5]. "Council of the European Union, basic measures for the radiation protection of persons undergoing medical examination or treatment, Directive 84/466/Euratom," 1984.

[6]. United Nations Scientific Committee on the Effects of Atomic Radiation, Sources and Effects of Ionizing Radiation, Report to the General Assembly, with Scientific AnnexesI, vol. 1, no. c. 2010.

[7]. I. O. Sharifat, I. and Olarinoye, "Patient entrance skin doses at minna and ibadan for common diagnostic radiological examinations," Bayero J. Pure Appl. Sci., 2(1). 2009, 1-5,

[8]. International Atomic Energy Agency, "Dosimetry in diagnostic radiology: an international code of practice. —Technical reports series, ISSN 0074-1914; no. 457 IAEA Vienna," 2007.

[9]. A. S. Jumaa Yousif Tamboul, Mohamed Yousef, Khadija Mokhtar, Ahmed Alfaki, "Assessment of Entrance Surface Dose for the Patients from Common Radiology Examinations in Sudan,” Igarss 2014, 11(1), 1-5,.

[10]. F. I. Habbani and I. I. Suliman, "Calculations of effective dose in diagnostic radiology," Sudan J. Basic Sci., 16, 2010, 121-134,

[11]. International Commission on Radiological Protection, "Diagnostic reference levels in medical imaging: review and additional advice.," Ann. ICRP, 31(4), 2001, 33-52,

[12]. Ibrahim Suliman Nada Ahmed and farouk I. Habbani, "Entrance surface Doses To patients Undergoing Selected Diagnostic X ray Examination in Sudan," Radiat. Prot. Dosimetry, 123(2), 2007, 209-214.

[13]. Abu KhiarA A, Hamza A O, and Abbas N A, "Dose Reference Levels in Radiography for the Most Common Examinations in Sudan," Sudan JMS, 11(1), 2016, 7-16.

[14]. D. K. Olivera Ciraj, Srpko Marković, "Patient dose from conventional diagnostic radiology procedures in serbia and montenegro," J. Prev. Med., 12, 2004, 26-34

[15]. A. Beganovi, A. Skopljak, A. Drljevi, S. Avdi, D. R. Levels, I. Commission, R. Protection, E. Commission, M. E. Directive, E. U. Guideline, and R. Sarajevo, "Initial Local Diagnostic Reference Levels for Conventional Radiological Procedures at the Institute of Radiology Sarajevo," J. Radiol., 11,1997.

[16]. A. Aroua, A. Besançon, I. Buchillier-Decka, P. Trueb, J.-F. Valley, F. R. Verdun, and W. Zeller, "Adult reference levels in diagnostic and interventional radiology for temporary use in Switzerland.," Radiat. Prot. Dosimetry, 111(3), 2004, 289-95.

[17]. D. Škrk, U. Zdešar, and D. Žontar, "Diagnostic reference levels for X-ray examinations in Slovenia," Radiol Oncol, 40, September, 2006, 189-196. 